\title{
Recent Progress in Tropical Cyclone Intensity Forecasting at the National Hurricane Center
}

\author{
John P. Cangialosi, Eric Blake, Mark DeMaria, Andrew Penny, Andrew Latto, \\ AND EDWARD RAPPAPORT \\ NOAA/NWS/NCEP National Hurricane Center, Miami, Florida \\ VIJAY TALLAPRAGADA \\ NOAA/NWS/NCEP Environmental Modeling Center, College Park, Maryland
}

(Manuscript received 20 April 2020, in final form 22 June 2020)

\begin{abstract}
It has been well documented that the National Hurricane Center (NHC) has made significant improvements in Atlantic basin tropical cyclone (TC) track forecasting during the past half century. In contrast, NHC's TC intensity forecast errors changed little from the 1970s to the early 2000s. Recently, however, there has been a notable decrease in TC intensity forecast error and an increase in intensity forecast skill. This study documents these trends and discusses the advancements in TC intensity guidance that have led to the improvements in NHC's intensity forecasts in the Atlantic basin. We conclude with a brief projection of future capabilities.
\end{abstract}

\section{Introduction}

The National Hurricane Center (NHC) makes and issues public forecasts for tropical depressions, tropical storms, and hurricanes, henceforth referred to as tropical cyclones (TCs) collectively, for the Atlantic and eastern North Pacific basins. Other centers, including the Central Pacific Hurricane Center, Joint Typhoon Warning Center, Japan Meteorological Agency, Indian Meteorological Department, France La Reunion, and Australian Bureau of Meteorology have similar responsibilities for $\mathrm{TC}$ forecasting for different parts of the world. NHC has a long history of making TC forecasts and related products, with the earliest quantitative forecasts known to the authors having been those issued for track for the 1-day (24-h) period beginning

\footnotetext{
${ }^{1}$ The name National Hurricane Center did not become official until the 1960s, though that moniker was employed informally in the 1950s. Sheets (1990) provides a more comprehensive discussion of NHC's history.
}

Corresponding author: John P. Cangialosi, john.p.cangialosi@ noaa.gov in $1954 .{ }^{1}$ Since then, NHC has extended the emporal horizon of its forecasts, currently to five days, and added predictions of TC intensity, size, and associated hazards, such as wind, storm surge, and rainfall. In addition, NHC has increased the lead times for the issuance of tropical storm and hurricane watches and warnings, and established the issuance of storm surge watches and warnings that are based in part on the forecast to give the public additional time to prepare for these potentially devastating hazards associated with TCs.

It has been well documented (McAdie and Lawrence 2000; Landsea and Cangialosi 2018) that NHC's track forecast errors have steadily decreased during the past several decades. Figure 1 shows the Atlantic basin track forecast errors averaged by decade for tropical storms and hurricanes. NHC's current average Atlantic basin track errors have been reduced by about half since the middle 1990s and by about two-thirds since the 1970s. Given the complexity of the issue and its great importance to society, it would not be unreasonable to characterize TC track forecast improvement as one of the greatest advances in Earth science of the past half century. The dramatic improvements in track prediction have been credited largely to gains made in numerical weather prediction (NWP) models whose outputs are 


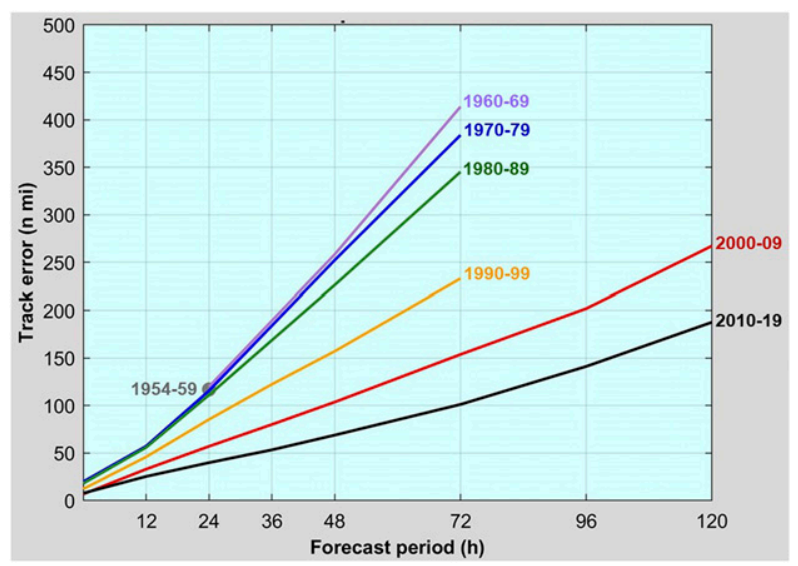

FIG. 1. NHC official track forecast errors ( $\mathrm{n} \mathrm{mi} ; 1 \mathrm{n} \mathrm{mi}=1.852 \mathrm{~km}$ ) averaged by decade for tropical storms and hurricanes. The $48-\mathrm{h}$ forecasts began in 1961, the 72-h forecasts began in 1964, the 36-h forecasts began in 1988, and the 96- and 120-h forecasts began in 2001.

provided as guidance to NHC forecasters (Powell and Aberson 2001; Goerss 2007).

It is important to distinguish between forecast error and forecast skill. Forecast intensity error is defined as the absolute value of the difference between the forecast and best track intensity at the forecast verifying time. Skill in an intensity forecast is assessed using Decay-SHIFOR5 as the baseline and is expressed as a percentage improvement over the baseline. The skill of a forecast $\mathrm{sf}$ is given by

$$
\operatorname{sf}(\%)=100 \times(e b-e f) / e b,
$$

where eb is the error of the baseline model and ef is the error of the forecast being evaluated. Skill is positive when the forecast error is smaller than the error from the baseline. The first step in obtaining the forecast is to run SHIFOR5 (Jarvinen and Neumann 1979; Knaff et al. 2003). Where the center is forecast to be over land, SHIFOR5 accounts for land interaction by applying the decay rate of DeMaria et al. (2006). The application of the decay component requires a forecast track, which is given by CLIPER5.

Even though track predictions have been improving for decades, intensity forecast errors dropped only slightly from the 1970s through the first decade of the 2000s. During that time period, the advancing technology and improving NWP track models did not lead to better intensity forecasts from NHC or the intensity models. Some details of the evolution of the intensity models are provided in the following sections. Decreasing intensity errors, however, have been noted in the past decade (Figs. 2 and 3a ). The recent reduction in error was also accompanied by an increase in forecast

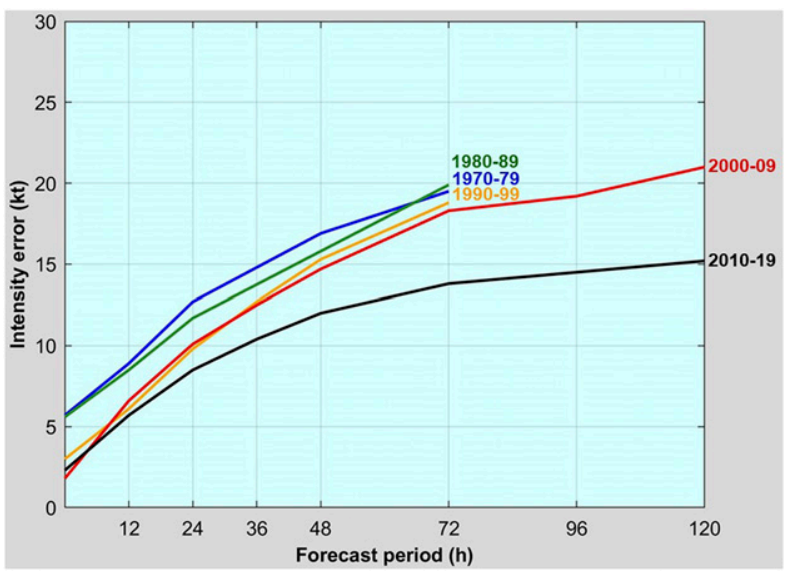

FIG. 2. NHC official intensity forecast errors (kt) averaged by decade for tropical storms and hurricanes. The 36 -h forecasts began in 1988, and the 96- and 120-h forecasts began in 2001.

skill (Fig. 3b) compared to the climatology and persistence intensity model Decay-SHIFOR5 (DeMaria et al. 2006). This model is analogous to the CLIPER5 model for track (Jarvinen and Neumann 1979; Knaff et al. 2003).

Decay-SHIFOR5 is currently used almost exclusively as an intensity skill benchmark at NHC, but that wasn't always the case. In another example of how times have changed (as driven by science), as recently as the 1990s the SHIFOR model provided both valued operational guidance as well as the baseline. This can be inferred from Fig. 3b where NHC's intensity forecast skill is shown to be of comparable magnitude to SHIFOR in those years because the remaining intensity forecast guidance available to NHC had little relative forecast skill (not shown).

This study explores the reasons behind the recent improvements in NHC's intensity forecasts and discusses what might occur in the next decade. The data used in the study are discussed in section 2 , and NHC and TC intensity model error trends are discussed in section 3. Consensus models and probabilistic intensity forecasts are discussed sections 4 and 5, respectively. Section 6 presents concluding remarks and some expectations for the future.

\section{Data and analysis methods}

For all operationally designated tropical or subtropical cyclones in the Atlantic and eastern North Pacific basins, NHC issues the U.S. government's official forecast of the cyclone's center location and maximum 1-min surface wind speed. Forecasts are routinely issued every $6 \mathrm{~h}$, and contain projections valid $12,24,36,48,72,96$, 

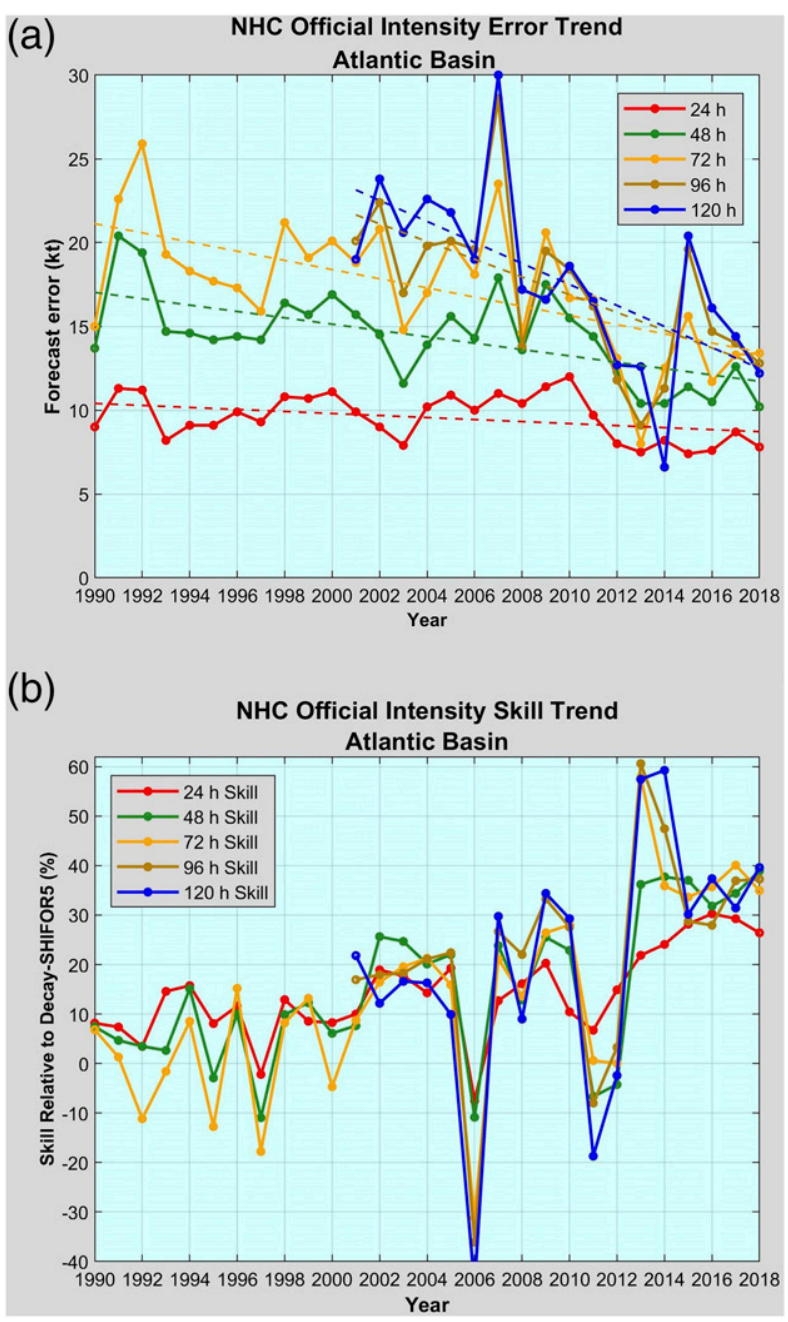

FIG. 3. Recent trends in NHC official intensity (a) forecast error (kt) and (b) skill for the Atlantic basin.

and $120 \mathrm{~h}^{2}$ after the forecast's nominal initial time (0000, 0600,1200 , or 1800 UTC). A forecast is "verified" only if the weather system is classified in the final "best track" (i.e., as NHC determines in its poststorm analysis) as a tropical (or subtropical) cyclone at both the forecast's initial time and at the projection's valid time. All other stages of development (e.g., tropical wave, [remnant] low, extratropical) are excluded. There are some occasions where NHC predicts a TC to intensify, but the system unexpectedly dissipates. For example, this was the case for Tropical Storm Erika in 2015 that was expected to strengthen before reaching Florida and instead dissipated on its approach. It should be noted that

\footnotetext{
${ }^{2} \mathrm{NHC}$ will begin issuing public 60 -h forecasts of TC position intensity, and 34- and 50-kt wind radii in 2020 .
}

these scenarios are excluded for the verification as only TCs at the initial and verification times are included.

Some forecast verification information is shown in Tables 1,3,4, and 5 as composite skill, which is the mean skill of a forecast or model calculated for all verifying cases over the entire forecast time. Results are also expressed in frequency of superior performance (FSP), which is a measure of the percentage of time in which one model or forecast produces a better prediction than the other, Decay-SHIFOR5 in this case. To provide more robust statistics, 95th percentile confidence intervals were also computed around the mean. It should be noted that the statistics shown here cover the entire Atlantic basin and do not separate errors by storm type, location, or environmental conditions. There has been and will continue to be ongoing research to look at the details of how the models perform in different regions and environments.

Multilayer dynamical models are generally, if not always, "late" models, meaning the 1200 UTC model (for example) is not available until after NHC's deadline to release the 1200 UTC forecast package at 1500 UTC. Fortunately, a technique exists to take the most recent available run of a late model (e.g., 0600 UTC in the current example) and adjust its forecast to apply to the current synoptic time and initial conditions. For example, forecast data for hours 6-126 from the previous (0600 UTC) run of the GFS would be smoothed and then adjusted, or shifted, such that the 6-h forecast (valid at 1200 UTC) would match the observed 1200 UTC position and intensity of the TC. The adjustment process creates an "early" version of the GFS model for the 1200 UTC forecast cycle that is based on the most current available guidance. The adjusted versions of the late models are known, mostly for historical reasons, as "interpolated models" (DeMaria and Gross 2003). The verification included here covers all tropical and subtropical cyclones from 1990 to 2019. It should be noted that the best tracks themselves are estimates and have some uncertainty associated with the intensity values (Landsea and Franklin 2013).

\section{NHC and tropical cyclone model forecast trends}

\section{a. Background}

Despite a fair amount of year-to-year variability, there is a notable improvement trend in NHC's intensity forecast skill that has been statistically significant and accelerating during the last several years (Fig. 3b, Table 1). Table 2 lists NHC's mean errors for each forecast time by decade and confidence intervals around the mean at the 95th percentile. It can be seen that the 
TABLE 1. Composite intensity skill and the frequency of superior performance of NHC's official forecast against Decay-SHIFOR5 averaged over the entire forecast period by decade.

\begin{tabular}{lcc}
\hline \hline \multicolumn{1}{c}{ Decades } & $\begin{array}{c}\text { Composite intensity skill of OFCL over } \\
\text { Decay-SHIFOR5 }\end{array}$ & $\begin{array}{c}\text { Frequency of superior performance of } \\
\text { OFCL over Decay-SHIFOR5 }\end{array}$ \\
\hline $1990-99(12-72 \mathrm{~h})$ & $9.4 \%$ & $56.2 \%$ \\
$2000-09^{\mathrm{a}}$ & $15.7 \%$ & $59.4 \%$ \\
$2010-19(12-120 \mathrm{~h})$ & $23.9 \%$ & $63.9 \%$ \\
\hline
\end{tabular}

a The 120 -h forecasts began in 2001 .

errors have dropped substantially in the 2010-19 period, especially after $36 \mathrm{~h}$, as compared to the prior two decades and that the improvements are statistically significant. Given the only modest decrease in intensity forecast errors between 1970 and 2000 (Fig. 2), the 25\%$30 \%$ drop in 120 -h forecast errors in just the most recent 10 years is especially impressive.

Much like the evolution of track forecast models a decade or two earlier, there has been a progression of the most accurate intensity forecast guidance coming from statistical models, then statistical-dynamical models, and finally dynamical models. As noted previously, prior to the middle 1990s NHC forecasters used primarily SHIFOR, a rudimentary statistical model based on climatology and persistence. Because little other quantitative intensity guidance existed during that period, and the limited skill of those models, we have chosen to restrict the evaluation of the intensity models to the period from 1996 to 2019. Although the primary purpose of this paper is to evaluate the progress of the intensity models, it should be noted that in addition to the intensity guidance, NHC forecasters evaluate trends in the available data (i.e., satellite, surface, aircraft) and incorporate that information into their shortterm predictions.

\section{b. The statistical-dynamical models era: 1996-2006}

During the 1996-2006 period, each of the previously mentioned forms of models made some contribution.
In addition to the purely statistical SHIFOR, whose relative value began to decrease, NHC relied on a combination of statistical-dynamical and regional dynamical hurricane models to predict TC intensity. During this time, global NWP models had little skill for intensity forecasting due in large part to their coarse horizontal resolution. During the 1990s and 2000s, one of the primary statistical-dynamical models used by NHC was the Statistical Hurricane Intensity Prediction Scheme (SHIPS; DeMaria and Kaplan 1994). The SHIPS model uses climatological, persistence, and synoptic predictors in a multiple regression scheme to forecast TC intensity, with the synoptic environmental conditions provided by the GFS model and its predecessor. SHIPS also includes predictors from ocean analyses and satellite imagery. Another model heavily used by NHC during this period was the Geophysical Fluid Dynamical Laboratory's hurricane prediction system (GFDL; Kurihara et al. 1998; Bender et al. 2019), which became operational in the middle 1990s. The GFDL hurricane model was the first operational model guidance used at NHC that attempted to dynamically forecast TC intensity and structure. From 1996 to 2006, SHIPS and GFDL were the only forecast models beyond SHIFOR providing intensity guidance to NHC forecasters. SHIPS had lower errors than GFDL annually at $48 \mathrm{~h}$ for 10 of those 11 years (Fig. 4). Table 3 shows a comparison of the composite skill and FSP of Decay-SHIFOR5, SHIPS and GFDL for the 1996-2006 period. This analysis

TABLE 2. NHC's mean intensity errors and 95th percent confidence intervals calculated by decade for all forecast times.

\begin{tabular}{|c|c|c|c|c|c|c|}
\hline $\begin{array}{l}\text { Forecast } \\
\text { time }(\mathrm{h})\end{array}$ & $\begin{array}{c}\text { 1990-99 mean } \\
\text { intensity } \\
\text { error }(\mathrm{kt})\end{array}$ & $\begin{array}{l}\text { 95th percent } \\
\text { confidence } \\
\text { interval }(\mathrm{kt})\end{array}$ & $\begin{array}{c}2000-09^{\mathrm{a}} \text { mean } \\
\text { intensity error }(\mathrm{kt})\end{array}$ & $\begin{array}{c}95 \mathrm{th}^{\mathrm{a}} \text { percent } \\
\text { confidence } \\
\text { interval }(\mathrm{kt})\end{array}$ & $\begin{array}{c}\text { 2010-19 mean } \\
\text { intensity } \\
\text { error }(\mathrm{kt})\end{array}$ & $\begin{array}{l}\text { 95th percent } \\
\text { confidence } \\
\text { interval }(\mathrm{kt})\end{array}$ \\
\hline 12 & 6.1 & $5.8-6.4$ & 6.6 & $6.3-6.9$ & 5.7 & $5.4-6.0$ \\
\hline 24 & 9.8 & $9.3-10.3$ & 10.1 & $9.6-10.6$ & 8.5 & $8.0-9.0$ \\
\hline 36 & 12.7 & $12.0-13.4$ & 12.5 & $11.8-13.2$ & 10.4 & 9.8-11.0 \\
\hline 48 & 15.3 & $14.4-16.2$ & 14.7 & $13.9-15.5$ & 12.0 & $11.3-12.7$ \\
\hline 72 & 18.8 & $17.6-20.0$ & 18.3 & $17.2-19.4$ & 13.8 & $12.8-14.8$ \\
\hline 96 & - & - & 19.3 & $17.9-20.7$ & 14.5 & $13.4-16.4$ \\
\hline 120 & - & - & 21.0 & $19.3-22.7$ & 15.2 & $14.0-16.4$ \\
\hline
\end{tabular}

\footnotetext{
${ }^{\text {a }}$ The 96- and 120-h forecasts began in 2001.
} 


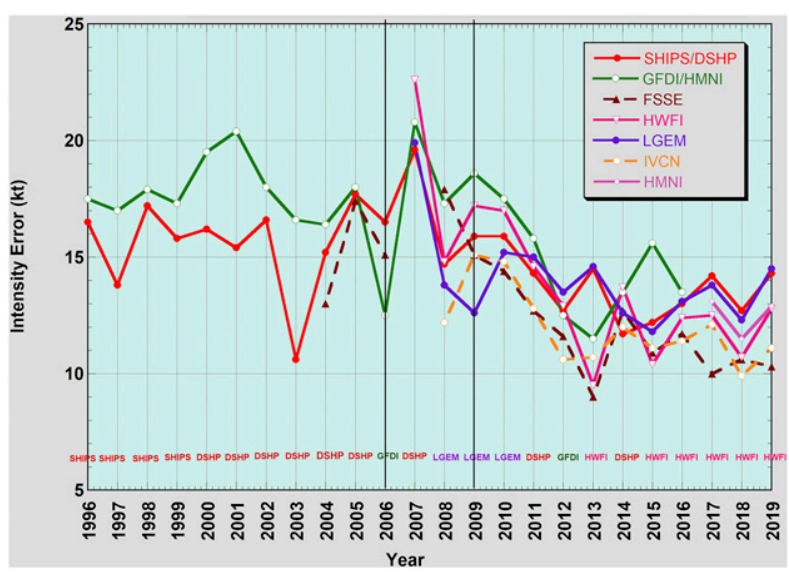

FIG. 4. Atlantic basin intensity model 48 -h errors (kt) averaged by year. The annual best-performing individual model is shown above the year. The first black line denotes when a change was noted in the intensity guidance from more statistical to more dynamical. The second black line shows when HFIP started.

shows that SHIPS had higher composite skill and FSP than GFDL. In fact, the GFDL model's skill was negative and the majority of the time it did not provide a better forecast than Decay-SHIFOR5, so it can be concluded that statistical-dynamical models were the best forecast aids during this era.

\section{c. Transition to dynamical models: (2007-19)}

Two more models became available at the NHC in 2007. The Logistic Growth Equation Model (LGEM), which uses data similar to that employed in the SHIPS model, but applies a different statistical-dynamical methodology to predict a TC's intensity became operational (DeMaria 2009). LGEM uses a time-stepping procedure rather than predicting the intensity change over the entire forecast interval as in the SHIPS model. This methodology better represents cases where the environment changes significantly during the forecast period, and cases where the TC center moves over land and then back over water. LGEM was successful from near the start, as it was the best-performing intensity model in the Atlantic basin at $48 \mathrm{~h}$ in 2008,2009 , and 2010. The dynamical Hurricane Weather Research and Forecast system (HWRF) also became operational in 2007 (Surgi 2008), but it did not outperform GFDL until the 2008-10 period (Fig. 4). Due to its relatively poor performance, GFDL was retired in 2017.

NOAA established the Hurricane Forecast Improvement Project (HFIP) in 2008 and Congress first appropriated funds for it the following year. HFIP's ambitious goals included reducing the average TC intensity forecast errors by $20 \%$ in 5 years and by $50 \%$ in 10 years for days 1-5 (Gall et al. 2013). Although all of those goals were
TABLE 3. Composite intensity skill and the frequency of superior performance of SHIPS and GFDL against Decay-SHIFOR5 averaged over the entire forecast period from 1996 to 2006.

\begin{tabular}{lcc}
\hline \hline Models & $\begin{array}{c}\text { Composite intensity skill of } \\
\text { over Decay-SHIFOR5 }\end{array}$ & $\begin{array}{c}\text { Frequency of superior } \\
\text { performance of over } \\
\text { Decay-SHIFOR5 }\end{array}$ \\
\hline SHIPS & $6.4 \%$ & $55.1 \%$ \\
GFDL & $-6.9 \%$ & $47.4 \%$ \\
\hline
\end{tabular}

not met, this program was undoubtedly part of the reason why NHC's intensity forecast errors have had their greatest decrease during the past decade. One of the big successes of HFIP has been the improvement of HWRF, which has become increasingly skillful and has been the most accurate TC intensity model for the Atlantic basin at the critical 48-h watch issuance lead time in 2013, and 2015-19 (Fig. 4).

Table 4 shows a comparison of composite skill and FSP of SHIPS, LGEM, and HWRF from 2007 to 2019. It can be seen that the skill over Decay-SHIFOR5 is slightly higher for SHIPS and LGEM than HWRF for this sample. However, if you confine the sample to the 2015-19 period, the composite skill and FSP of HWRF is highest, albeit only slightly for FSP (Table 5). These statistics are indicative of the progress of the dynamical models and how they have become competitive and even outperformed the statistical-dynamical aids in recent years.

NHC forecasters have done quite well in adding forecast value to objective guidance for TC intensity, and the official forecasts often have higher skill than any individual model. Figure 5 shows a series of consecutive 3 -yr averages of NHC and TC intensity model skill for the Atlantic basin. The purpose of using 3-yr averages is to build up a sufficient sample to make a fair comparison of the guidance and NHC's forecasts, and span a period long enough to account for different intensity of storms, which often changes from year to year. It can be seen that on average, the NHC forecast is near or better than the top-performing individual models for each sample, and that the skill of both the NHC forecast and the

TABLE 4. Composite intensity skill and the frequency of superior performance of SHIPS, LGEM, and HWRF against DecaySHIFOR5 averaged over the entire forecast period from 2007 to 2019 .

\begin{tabular}{lcc}
\hline \hline Models & $\begin{array}{c}\text { Composite intensity skill of } \\
\text { over Decay-SHIFOR5 }\end{array}$ & $\begin{array}{c}\text { Frequency of superior } \\
\text { performance over } \\
\text { Decay-SHIFOR5 }\end{array}$ \\
\hline SHIPS & $12.9 \%$ & $57.5 \%$ \\
LGEM & $13.0 \%$ & $57.6 \%$ \\
HWRF & $10.8 \%$ & $55.1 \%$ \\
\hline
\end{tabular}


TABLE 5. Composite intensity skill and the frequency of superior performance of SHIPS, LGEM, and HWRF against Decay-SHIFOR5 averaged over the entire forecast period from 2015 to 2019.

\begin{tabular}{lcc}
\hline \hline Models & $\begin{array}{c}\text { Composite intensity skill of } \\
\text { over Decay-SHIFOR5 }\end{array}$ & $\begin{array}{c}\text { Frequency of superior } \\
\text { performance over } \\
\text { Decay-SHIFOR5 }\end{array}$ \\
\hline SHIPS & $18.5 \%$ & $61.0 \%$ \\
LGEM & $19.7 \%$ & $61.9 \%$ \\
HWRF & $23.7 \%$ & $62.0 \%$ \\
\hline
\end{tabular}

models has been increasing over the years. An additional item of interest is that the GFS has very recently become skillful for TC intensity prediction, which no global model had accomplished previously (Chen et al. 2019). We point out that although this study is focused on the Atlantic basin, similar improvements have occurred in the eastern North Pacific basin over the past decade or so (not shown).
DeMaria (2010) showed that retrospectively replacing the forecast track with the observed track in the LGEM model improved that model's intensity forecasts by up to $30 \%$, with the largest improvements at the longer forecast periods. This suggests that some of the improvements in track forecasting have likely translated into better NHC intensity forecasts as well, though the correlation between NHC's track and intensity errors, while positive, is small-less than 0.2 at all forecast times from 2010 to 2019 over the entire Atlantic basin (not shown). Armed with a better track prediction, the forecaster can more accurately know where the TC will be located relative to the forecast environmental conditions and land interaction which affect TC intensity. While the modest correlation coefficient suggests that this is perhaps not critical all of the time, it can in some instances have an enormous effect on intensity forecast accuracy. One example of this is when the center of a TC is forecast to cross the coast and remain inland, rather
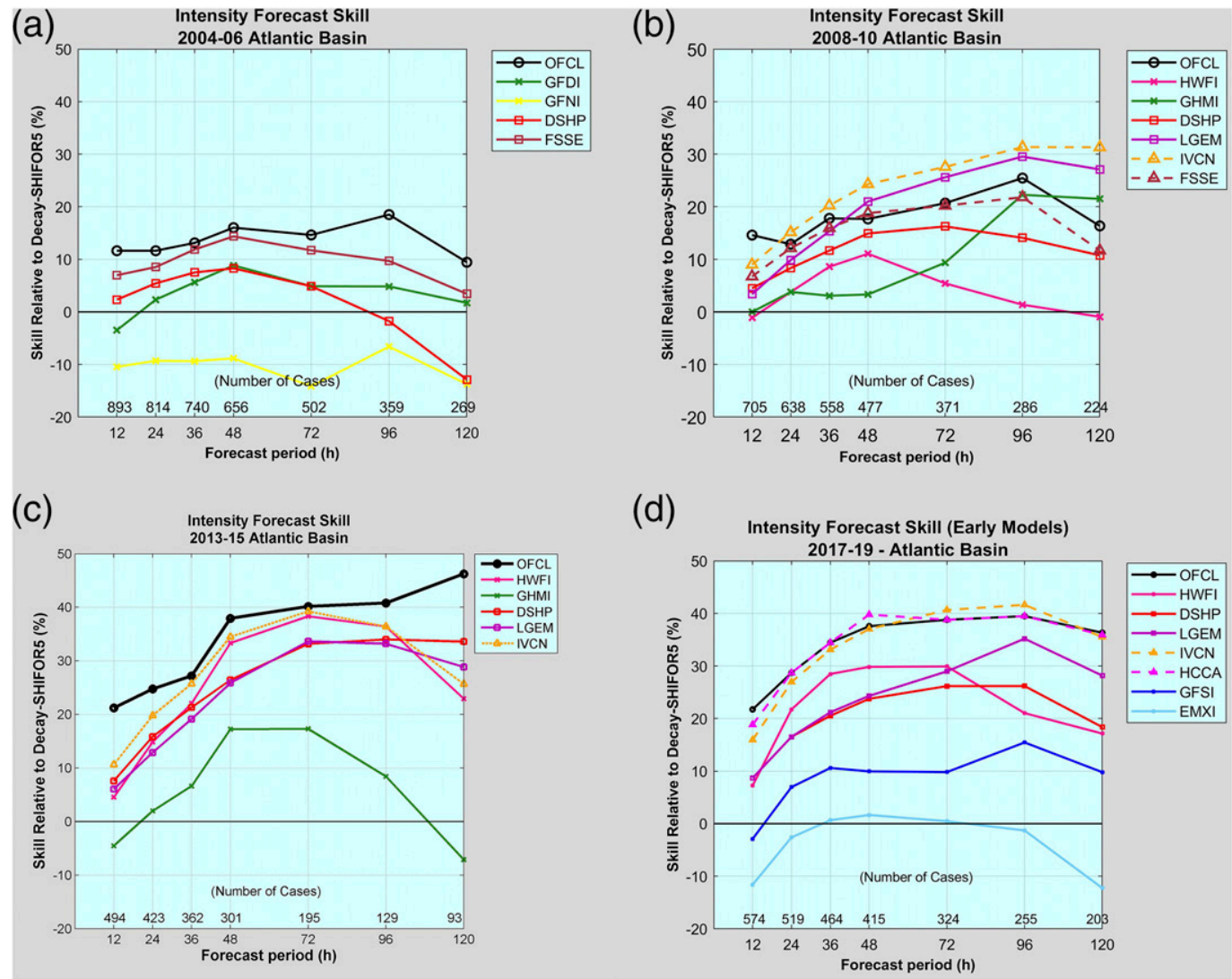

FIG. 5. NHC and intensity model skill for (a) 2004-06, (b) 2008-10, (c) 2013-15, and (d) 2017-19. NHC skill is shown in black, and the various models are depicted in the other colors. The number of verifying events at each forecast lead time is shown above the $x$ axis. Models not previously defined: NHC forecasts (OFCL), HWRF interpolated forecasts (HWFI), GFDL interpolated forecasts (GFDI), GFDL run off the U.S. Navy Global Atmospheric Prediction System (GFNI), Florida State Super Ensemble (FSSE), GFS interpolated forecasts (GFSI), and ECMWF interpolated forecasts (EMXI). 
than staying offshore (or vice versa), because a TC's maximum wind speed decreases typically by around $50 \%$ during the first $12 \mathrm{~h}$ after the center crosses the coastline and remains inland. Forecasting the center to be on the "wrong" side of the coast can result in very large intensity forecast errors.

\section{Consensus models}

\section{a. Background}

In NHC's early years its forecasters were challenged by having few NWP models available to consider in their efforts to produce the best official forecast. As the number of skillful track forecast models increased in the 1970s-90s, however, they became faced with a new challenge: how to make the best use of multiple models that sometimes provided a wide geographical range of guidance tracks. Lacking a priori knowledge of which model outcomes were likely to be the most accurate, NHC usually forecast the track to be within the geographic spread of the typically best-performing models, often not far from the middle as they could determine subjectively. The forecasters came to realize that that approach over the long haul led to smaller errors than of any of the individual models. Software was then developed to provide to the forecaster arithmetic averages of the typically best-performing computer model forecasts (Sampson and Schrader 2000). These so-called consensus models have led the way in track forecasting accuracy during most of the past 15 years.

Beginning in 2008, NHC had a sufficient number of intensity models to create an intensity consensus. There are today two types of consensus aids. Both are discussed below and each has its advantages. A "simple" consensus model equally weights each member (Sampson et al. 2008). A corrected consensus often weights models differently and considers past error characteristics in attempting to correct for member biases.

\section{b. Simple consensus models-Intensity variable model consensus (IVCN)}

The intensity variable consensus model (IVCN) was one of the first simple consensus aids used in NHC operations. In 2008, the makeup of IVCN was a fourmember average of SHIPS, LGEM, and the interpolated early versions of the GFDL and HWRF models. The consensus model was quite successful that year, as it had more skill than any of individual members and slightly more skill than NHC (Fig. 4) (Franklin 2009). It should be mentioned that IVCN is a variable consensus model, meaning the composition of the consensus changes based on model availability. For example, it is sometimes the case that the 120 -h forecast is based on a different set of members than the 12-h forecast. At the conclusion of every hurricane season, NHC evaluates IVCN, looks at the performance of alternatives, and makes adjustments accordingly. As of this writing, IVCN is a five-member model that includes equal weighting of SHIPS, LGEM, and the interpolated early versions of HWRF, Hurricanes in a Multiscale OceanCoupled Nonhydrostatic model (HMON), and the version of the U.S. Navy's Coupled Ocean-Atmosphere Mesoscale Prediction System for TCs that uses GFS initial and boundary conditions (CTCX). Because of the improvement in the dynamical models (e.g., Fig. 5), a new consensus aid, IVDR, was first computed at NHC in 2018. The composition of this model includes a doubleweight for the interpolated versions of CTCX, HWRF, and HMON, and single weight for the interpolated version of GFS, SHIPS, and LGEM. During the past couple of hurricane seasons, IVDR has generally had slightly more skill than IVCN (not shown).

\section{c. Corrected consensus models-HFIP corrected consensus approach (HCCA)}

Beginning in 2015, the HFIP corrected consensus approach (HCCA) was implemented at NHC to provide "in-house" track and intensity forecast guidance (Simon et al. 2018). The consensus is broadly based on the technique used in the Florida State Superensemble (see Krishnamurti et al. 1999, 2010, 2011, and Williford et al. 2003) but specifically tailored to NHC's operational constraints. Since 2015, HCCA has been one of the best performing guidance models for track and intensity in the Atlantic basin (Fig. 5d).

The HCCA intensity forecasts rely on a mix of statistical-dynamical and dynamical model forecasts that are basin specific. Unequal weighting coefficients are derived from a set of training forecasts and applied to the input model predictions to create the HCCA forecast. To allow for operational flexibility, a forecast-specific training set is created in real time to match the input model availability of the current forecast. Based on input model sensitivity experiments, the HWRF and CTCX forecasts currently make the largest contribution to the positive skill of the HCCA intensity forecasts in the Atlantic basin. It is hoped that continued improvement of the equally weighted and corrected consensus aids will allow for further improvements in skill of the NHC intensity forecasts.

\section{Probabilistic intensity guidance and rapid intensification}

Although the statistical-dynamical models have improved over the past two decades, they rarely predict 


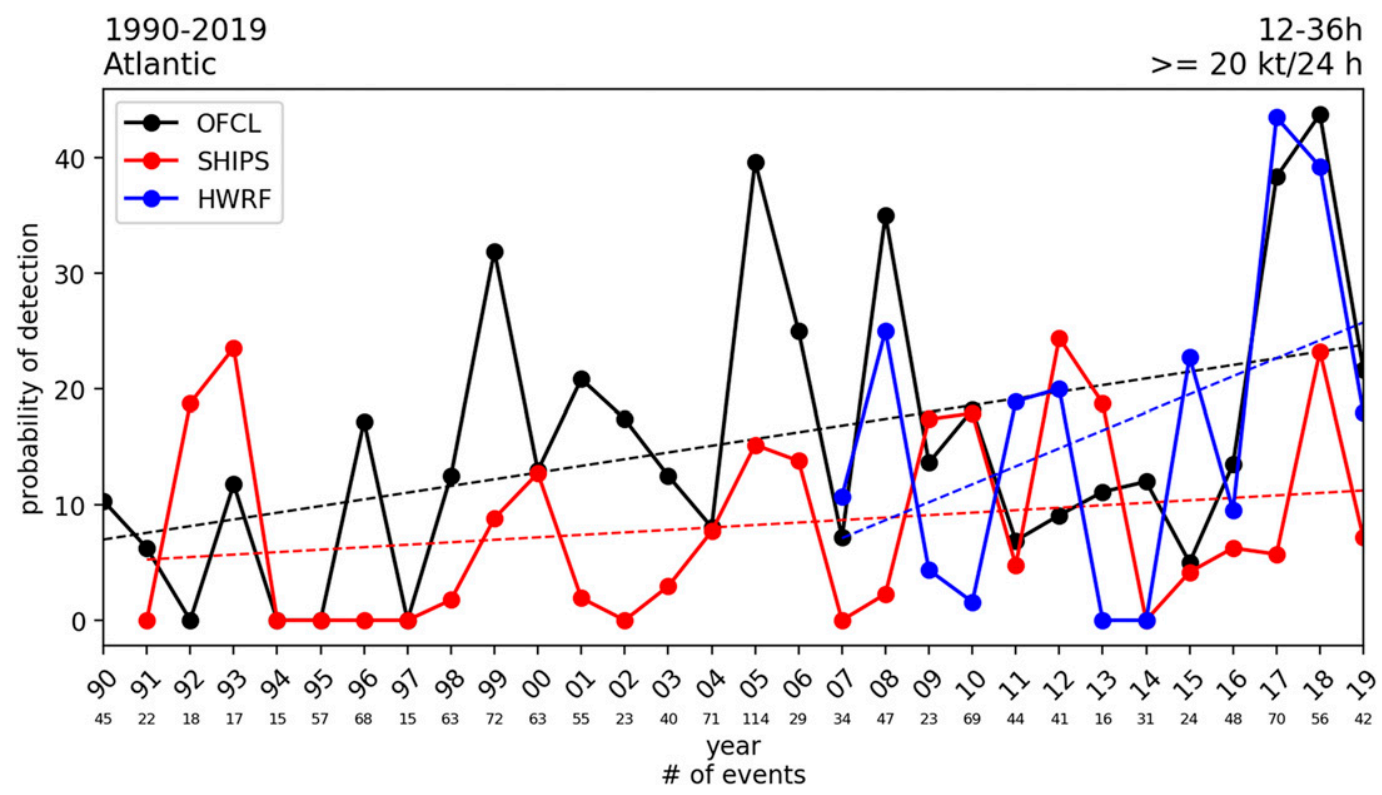

FIG. 6. Probability of detection for intensification rates of $20 \mathrm{kt}$ or greater over the 24-h forecast period of 12-36 h. Trend lines are shown for the NHC official forecast (OFCL; black), SHIPS (red), and the HWRF (blue). Forecasts from SHIPS and HWRF began in 1991 and 2007, respectively, and early model forecasts were used in HWRF. The number of verifying events for each year is shown below the $x$ axis.

rapid intensity changes. Also, the limited horizontal resolution of the GFDL and early versions of the HWRF model restricted the ability of these two models to predict large changes. Without reliable guidance, the NHC official forecast rarely included large changes in intensity (Blake et al. 2016). To partially address the limitation of the statistical-dynamical models, a new component was added to the SHIPS model called the rapid intensification index (RII), beginning in 2001 (Kaplan and DeMaria 2003). Rapid intensification (RI) was defined as a $30-\mathrm{kt}\left(1 \mathrm{kt} \approx 0.51 \mathrm{~m} \mathrm{~s}^{-1}\right)$ or greater increase in the maximum wind speed in $24 \mathrm{~h}$, based roughly on the 95th percentile of the observed intensity changes in the Atlantic basin. The RII treats RI forecasting as a classification problem, where a subset of the SHIPS predictors are used to discriminate RI cases from non-RI cases. The output of the RII is a probability of rapid intensification, which forecasters subjectively use to supplement deterministic model output. The RII has improved since the initial 2001 version (Kaplan et al. 2015).

The probability of detection (POD) for intensification rates of $20 \mathrm{kt}$ or greater over the 24-h forecast period of 12-36 h is shown in Fig. 6 for the NHC official forecasts (OFCL), SHIPS, and HWRF from 1990 to 2019 (SHIPS and HWRF forecasts began in 1991 and 2007, respectively). Using a 20 -kt or greater threshold dramatically increases the sample size [compared to the strict definition of $\geq 30 \mathrm{kt}(24 \mathrm{~h})^{-1}$ for $\left.\mathrm{RI}\right]$ to ensure more meaningful results. Despite the large amount of year-toyear variability, OFCL and HWRF exhibited a positive trend of increasing POD for these events. For HWRF, increasing horizontal grid resolution (e.g., the horizontal grid spacing of the innermost nest of HWRF decreased from 3 to $2 \mathrm{~km}$ in 2015, and then to $1.5 \mathrm{~km}$ in 2018) and improvements to the physical parameterizations and data assimilation techniques have helped the model resolve these intensification rates while limiting false alarms. These improvements in model guidance and the introduction of RI probability guidance (e.g., RII) has provided NHC forecasters with the ability to better discriminate between real and false intensification events in model predictions, helping to improve the POD. Despite the improvements in POD over recent years, Fig. 7 shows that there has been no notable trend in the false alarm rates for the same short-term intensification rates of $20 \mathrm{kt}$ or greater in the NHC forecasts or SHIPS and HWRF models.

\section{Summary and expectations for the future}

Although TC track forecasting has improved steadily over the past several decades, intensity forecasts showed little increase in accuracy until around 2010. The advancement of NWP models, especially as supported in the past decade by HFIP, creation of the consensus aids, development of RI guidance, and the ability of the NHC 


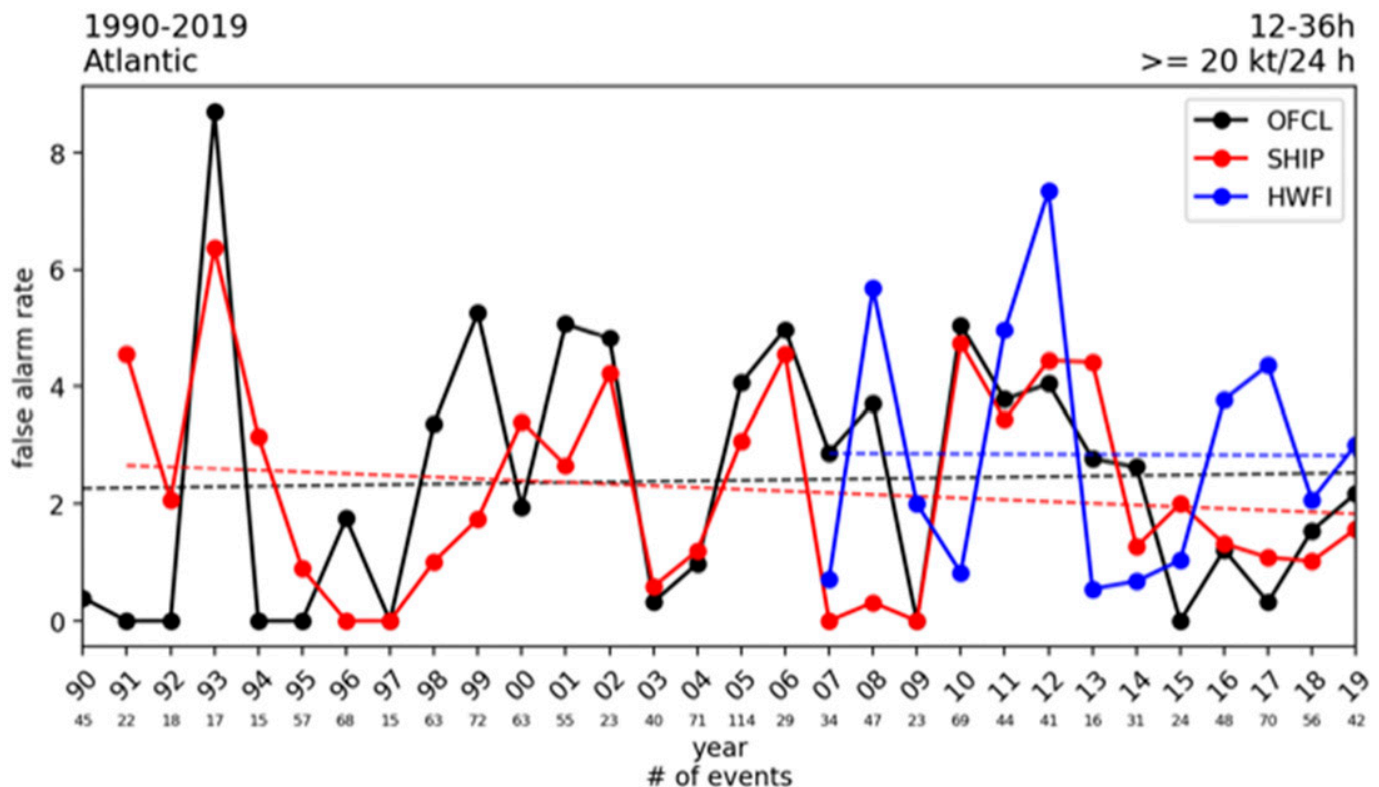

FIG. 7. False alarm rate for intensification rates of $20 \mathrm{kt}$ or greater over the 24 -h forecast period of $12-36 \mathrm{~h}$. Trend lines are shown for the NHC official forecast (OFCL, black), SHIPS (red), and the HWRF (blue). Forecasts from SHIPS and HWRF began in 1991 and 2007, respectively, and early model forecasts were used in HWRF. The number of verifying events for each year is shown below the $x$ axis.

forecasters to add value to the TC guidance has greatly improved intensity forecast skill.

The authors expect that NHC intensity forecasts will continue to become more accurate during the next decade or so, but further increases in accuracy will be limited by the uncertainty in the intensity analysis (Landsea and Franklin 2013) and eventually by limits of predictability. It is expected that the dynamical models, and in particular the global models, will become increasingly used for operational intensity forecasting and positively contribute to NHC's intensity forecasts. Much work still needs to be done to further improve RI forecasting, and as new and existing tools are developed and refined, there should be an increasing confidence in applying RI forecasts in operations. One such tool that could potentially aid in RI forecasting is the HWRF Finite Volume Hurricane Nest model, which has been utilized in a study by NOAA's Atlantic Oceanic and Meteorological Laboratory to predict the RI of Hurricane Michael (Hazelton et al. 2020). Recent advancements in the ability to incorporate tail Doppler radar data from reconnaissance aircraft into the HWRF model ( $\mathrm{Lu}$ et al. 2020) and by adding more detailed satellite observations in model initializations, we will hopefully observe continued improvements in model TC intensity predictions. Corrected consensus models will also likely improve as the contributing models continue to advance. A number of research studies using machine learning techniques, which can better represent nonlinear processes like TC intensity change, are also showing some promise for intensity prediction (e.g., Cloud et al. 2019; Schaffer et al. 2020).

Acknowledgments. This work took place at the National Hurricane Center. The authors thank Michael Brennan, Chris Landsea, Matthew Onderlinde, and Brian Zachary for reviewing this work.

\section{REFERENCES}

Bender, M. A., T. Marchok, R. E. Tuleya I. Ginnis, V. Tallapragada, and S. J. Lord, 2019: Hurricane model development at GFDL: A collaborative success story from an historical perspective. Bull. Amer. Meteor. Soc., 100, 1725-1736, https://doi.org/10.1175/ BAMS-D-18-0197.1.

Blake, E. S., J. P. Cangialosi, and P. J. Klotzbach, 2016: Is NHC intensity forecast skill increasing? 32nd Conf. on Hurricanes and Tropical Meteorology, San Juan, Puerto Rico, Amer. Meteor. Soc., https://ams.confex.com/ams/32Hurr/webprogram/ Paper293532.html.

Chen, J.-H., and Coauthors, 2019: Advancements in hurricane prediction with NOAA's next-generation forecast system. Geophys. Res. Lett., 46, 4495-4501, https://doi.org/10.1029/2019GL082410.

Cloud, K. A., B. J. Reich, C. M. Rozoff, S. Aleesandrini, W. E. Lewis, and L. Delle Monache, 2019: A feed forward neural network based on model output statistics for short-term hurricane intensity prediction. Wea. Forecasting, 34, 985-997, https://doi.org/10.1175/WAF-D-18-0173.1.

DeMaria, M., 2009: A simplified dynamical system for tropical cyclone intensity prediction. Mon. Wea. Rev., 137, 68-82, https://doi.org/10.1175/2008MWR2513.1. 
- 2010: Tropical cyclone intensity change predictability estimates using a statistical-dynamical model. 29th Conf. on Hurricanes and Tropical Meteorology, Tucson, AZ, Amer. Meteor. Soc., 9C.5, https://ams.confex.com/ams/29Hurricanes/ techprogram/paper_167916.htm.

, and J. Kaplan, 1994: A Statistical Hurricane Intensity Prediction Scheme (SHIPS) for the Atlantic basin. Wea. Forecasting, 9, 209-220, https://doi.org/10.1175/1520-0434(1994) 009\%3C0209:ASHIPS\%3E2.0.CO;2.

— model. Hurricane! Coping with Disaster: Progress and Challenges since Galveston 1900, Robert Simpson et al. Eds., Wiley, 103-126.

— , J. A. Knaff, and J. Kaplan, 2006: On the decay of tropical cyclone winds crossing narrow landmasses. J. Appl. Meteor. Climatol., 45, 491-499, https://doi.org/10.1175/JAM2351.1.

Franklin, J. L., 2009: 2008 National Hurricane Center forecast verification report. NOAA/National Hurricane Center Rep. 71 pp., https://www.nhc.noaa.gov/verification/pdfs/Verification_2008.pdf.

Gall, R., J. Franklin, F. Marks, E. N. Rappaport, and F. Toepfer, 2013: The Hurricane Forecast Improvement Project. Bull. Amer. Meteor. Soc., 94, 329-343, https://doi.org/10.1175/BAMSD-12-00071.1.

Goerss, J. S., 2007: Prediction of consensus tropical cyclone track forecast error. Mon. Wea. Rev., 135, 1985-1993, https://doi.org/ 10.1175/MWR3390.1.

Hazelton, A., X. Zhang, S. Gopalakrishnan, W. Ramstrom, F. Marks, and J. Zhang, 2020: High-resolution ensemble HVF3 forecasts of Hurricane Michael (2018): Rapid intensification in shear. Mon. Wea. Rev., 148, 2009-2032, https:// doi.org/10.1175/MWR-D-19-0275.1.

Jarvinen, B. R., and C. J. Neumann, 1979: Statistical forecasts of tropical cyclone intensity for the North Atlantic basin. NOAA Tech. Memo. NWS NHC-10, 22 pp.

Kaplan, J., and M. DeMaria, 2003: Large-scale characteristics of rapidly intensifying tropical cyclones in the North Atlantic basin. Wea. Forecasting, 18, 1093-1108, https://doi.org/10.1175/ 1520-0434(2003)018<1093:LCORIT>2.0.CO;2.

—_, and Coauthors, 2015: Evaluating environmental impacts on tropical cyclone rapid intensification predictability utilizing statistical models. Wea. Forecasting, 30, 1374-1396, https:// doi.org/10.1175/WAF-D-15-0032.1.

Knaff, J. A., M. DeMaria, B. Sampson, and J. M. Gross, 2003: Statistical, 5-day tropical cyclone intensity forecasts derived from climatology and persistence. Wea. Forecasting, 18, 80-92, https:// doi.org/10.1175/1520-0434(2003)018<0080:SDTCIF >2.0.CO;2.

Krishnamurti, T. N., C. M. Kishtawal, T. LaRow, D. Bachiochi, Z. Zhang, C. E. Williford, S. Gadgil, and S. Surendran, 1999: Improved weather and seasonal climate forecasts from multimodel superensemble. Science, 285, 1548-1550, https://doi.org/ 10.1126/science.285.5433.1548.

, S. Pattnaik, M. K. Biswas, E. Bensman, M. Kramer, N. Surgi, and T. S. V. V. Kumar, 2010: Hurricane forecasts with a mesoscale suite of models. Tellus, 62A, 633-646, https://doi.org/ 10.1111/j.1600-0870.2010.00469.x.

_ Ruscher, 2011: Hurricane forecasts using a suite of large-scale models. Tellus, 63A, 727-745, https://doi.org/10.1111/j.16000870.2011.00519.x.

Kurihara, Y., R. E. Tuleya, and M. A. Bender, 1998: The GFDL hurricane prediction system and its performance in the 1995 hurricane season. Mon. Wea. Rev., 126, 1306-1322, https:// doi.org/10.1175/1520-0493(1998)126<1306:TGHPSA > 2.0.CO;2.

Landsea, C. W., and J. L. Franklin, 2013: Atlantic hurricane database uncertainty and presentation of a new database format. Mon. Wea. Rev., 141, 3576-3592, https://doi.org/10.1175/ MWR-D-12-00254.1.

— predictability for tropical cyclone track forecasting? Bull. Meteor. Amer. Soc., 99, 2237-2243, https://doi.org/10.1175/ BAMS-D-17-0136.1.

Lu, X., and W. Xuguang, 2020: Improving hurricane analyses and predictions with TCI, IFEX field campaign observations, and CIMSS AMVs using the advanced hybrid data assimilation system for HWRF. Part II: Observation impacts on the analysis and Prediction of Patricia (2015). Mon. Wea. Rev., 148, 1407-1430, https://doi.org/10.1175/MWR-D-19-0075.1.

McAdie, C. J., and M. B. Lawrence, 2000: Improvements to tropical cyclone track forecasting in the Atlantic basin, 1970-98. Bull. Amer. Meteor. Soc., 81, 989-998, https://doi.org/10.1175/ 1520-0477(2000)081<0989:IITCTF>2.3.CO;2.

Powell, M. D., and S. D. Aberson, 2001: Accuracy of United States tropical cyclone landfall forecasts in the Atlantic basin, 19762000. Bull. Amer. Meteor. Soc., 82, 2749-2767, https://doi.org/ 10.1175/1520-0477(2001)082<2749:AOUSTC>2.3.CO;2.

Sampson, C. R., and A. J. Schrader, 2000: The Automated Tropical Cyclone Forecasting System (version 3.2). Bull. Amer. Meteor. Soc., 81, 1231-1240, https://doi.org/10.1175/1520-0477(2000) 081<1231:TATCFS $>2.3$. CO;2.

—_, J. L. Franklin, J. A. Knaff, and M. DeMaria, 2008: Experiments with a simple tropical cyclone intensity consensus. Wea. Forecasting, 23, 304-312, https://doi.org/10.1175/ 2007WAF2007028.1.

Schaffer, J. D., P. J. Roebber, and C. Evans, 2020: Development and evaluation of an evolutionary programming-based tropical cyclone intensity model. Mon. Wea. Rev., 148, 1951-1970, https://doi.org/10.1175/MWR-D-19-0346.1.

Sheets, R. C., 1990: The National Hurricane Center-Past, present, and future. Wea. Forecasting, 5, 185-232, https://doi.org/ 10.1175/1520-0434(1990)005<0185:TNHCPA > 2.0.CO;2.

Simon, A., A. B. Penny, M. DeMaria, J. L. Franklin, R. J. Pasch, E. N. Rappaport, and D. A. Zelinsky, 2018: A description of the real-time HFIP Corrected Consensus Approach (HCCA) for tropical cyclone track and intensity guidance. Wea. Forecasting, 33, 37-57, https://doi.org/10.1175/WAF-D-17-0068.1.

Surgi, N., 2008: Advanced hurricane prediction at NCEP's Environmental Model Center: The operational implementation of the HWRF. NCEP, 32 pp.

Williford, C. E., T. N. Krishnamurti, R. C. Torres, S. Cocke, Z. Christidis, and T. S. V. Kumar, 2003: Real-time multimodel superensemble forecasts of Atlantic tropical systems of 1999. Mon. Wea. Rev., 131, 1878-1894, https://doi.org/10.1175//2571.1. 